\title{
ПРОТИВОДЕЙСТВИЕ КОРРУПЦИИ В УСЛОВИЯХ ЦИФРОВОЙ ЭКОНОМИКИ
}

\author{
(C) 2020 Чернов Сергей Борисович \\ кандидат экономических наук, \\ доцент кафедры мировой экономики и международных экономических отношений \\ Государственный университет управления, Россия, Москва \\ Email: chernov_s_b@mail.ru
}

Дана современная трактовка причин коррупции. Рассмотрены и систематизированы формы коррупции. Установлена связь между цифровизацией экономики и угрозами для противодействия коррупции. Обсуждаются функции государства в области противодействия коррупции в условиях цифровой экономики.

Ключевые слова: коррупция, теневая экономика, цифровая экономика, криптовалюта.

Коррупция в той или иной форме и степени свойственна всем странам мира. По данным $\mathrm{OOH}$, ежегодный объем взяток в мире составляет 1 трлн. долл. США, а ущерб от коррупционного поведения должностных лиц достигает 2,6 трлн. долл. США [1]. В России в 2019 году было зарегистрировано почти 31 тыс. преступлений коррупционной направленности, ущерб от которых составил около 55,1 млрд. руб. [2]. Поэтому вырабатываются меры по усилению противодействия коррупционному поведению должностных лиц, активизируется раскрытие и расследование коррупционных преступлений.

Однако увеличение ответственности за коррупционные преступления в Российской Федерации не изменили кардинально в лучшую сторону общественные отношения. Более того, выявляемая в стране коррупция увеличивается второй год подряд, «откаты» в области закупок выросли почти в 2 раза, а взятки - на $11 \%$ [3]. В России по-прежнему к наиболее коррупционным сферам деятельности относятся освоение бюджетных средств, в том числе выделенных в рамках целевых программ, организация торгов, управление имуществом, контрольноревизионная, правоохранительная деятельность и жилищно-коммунальное хозяйство. Следовательно, причины коррупции продолжают сохраняться и носят многогранный характер. К таким причинам относятся:

1. Коррупционный оппортунизм субъектов рынка, под которым понимается получение конкурентных преимуществ и извлечение дополнительных доходов за счет коррупционного поведения.

2. Так называемый «эффект коррупции» как частное проявление «эффекта нарушителя», в результате которого происходит увеличение числа участников коррупционных отношений вследствие экономической привлекательности и выгодности коррупционного поведения.

3. Негативное с точки зрения общества разрешение конфликта интересов должностных лиц как следствие прямой, а так же косвенной их личной заинтересованности, что разрушает объективное, беспристрастное и честное исполнение ими своих должностных обязанностей.

4. Теневые доходы в обществе, которые накапливаются и ищут сферы своего прибыльного приложения и привносят в общественные отношения нравы и традиции теневой экономики.

5. Институциональные несоответствия и противоречия. Например, установление заработной платы должностным лицам ниже стоимости их рабочей силы, асимметричность информации на рынках, а также отсутствие регламента поведения должностных лиц в той или иной ситуации могут порождать коррупционное поведение людей.

Коррупция - это использование каким-либо должностным лицом своих властных полномочий и доверенных ему прав в целях личного обогащения либо извлечения выгоды в материальной либо иной форме. В настоящее время законодательно определено понятие коррупции, под которой понимается злоупотребление служебным положением, дача взятки, получение взятки, злоупотребление полномочиями, коммерческий подкуп либо иное незаконное использование физическим лицом своего должностного положения вопреки законным интересам общества и государства в целях по- 
лучения выгоды в виде денег, ценностей, иного имущества или услуг имущественного характера, иных имущественных прав для себя или для третьих лиц либо незаконное предоставление такой выгоды указанному лицу другими физическими лицами, а также совершение данных деяний от имени или в интересах юридического лица [4].

Источником коррупции является административная власть должностного лица над каким-либо вверенным ему в управление ресурсом. С увеличением закрытости механизма управления ресурсом источник коррупции увеличивается, возрастает потенциальная возможность коррупционных деяний со стороны должностных лиц. Цифровизация государственного и муниципального управления позволяет исключить или максимально ограничить непосредственный контакт должностных лиц государственных и муниципальных органов власти с физическими и юридическими лицами, а также сделать достаточно прозрачным механизм управления ресурсами.

Коррупция многогранна и может проявляться в различных формах. Во-первых, она может выступать как бытовая, деловая и политическая коррупция. В основе данного деления лежит сфера деятельности индивидуумов. В быту она может проявляться, например, при устройстве детей в образовательные учреждения или при регистрации нового автомобиля. Бытовая коррупция наиболее видимая часть коррумпированных общественных отношений, потому что люди в своей обычной жизнедеятельности не выступают робинзонами, а взаимодействуют с представителями государственных и муниципальных органов власти.

Сфера существования деловой коррупции включает в себя прежде всего коррумпированные производственные отношения в предпринимательской деятельности. В качестве примера можно привести незаконное получение лицензий и государственных заказов. Деловая коррупция возможна и вне предпринимательской деятельности, так как государство и муниципалитеты могут выступать активными субъектами деловых отношений. Например, к деловой коррупции можно отнести трудоустройство на работу по так называемому «блату», продвижение сотрудников по служебной лестнице не в результате оценки их деловых качеств, а путем подкупа должностных лиц ценными подарками. Громкие разоблачения высокопоставленных коррупционеров свидетельствуют о том, что на рынке труда по-прежнему не изжиты кумовство, протекционизм и другие коррупционные способы продвижения по службе.

Политическая коррупция охватывает политическую сферу жизнедеятельности общества и может обеспечить проникновение в законодательные органы власти субъектов криминальной экономики и сторонников экстремистских, террористических организаций.

Во-вторых, коррупция может сформироваться во всех секторах экономики: государственном, муниципальном, частном и смешанном. Соответственно этому можно выделить четыре формы коррупции, которые поражают не только производственные отношения внутри каждого сектора экономики, но и разрушают механизм государственного регулирования экономики в целом.

В настоящее время существует недооценка ущерба, наносимого коррупцией в частном секторе экономики. Значимость частного сектора для общества определяется тем, что изначально частный труд в ходе своего успешного функционирования превращается в частичку общественного труда. Таким образом, общественный характер частного труда опосредуется рынком, при этом участники рыночных отношений склонны к оппортунистическому поведению.

В настоящее время общество часто сталкивается с последствиями нечестных методов конкуренции, применяемых некоторыми организациями. Одним из таких нечестных методов конкурентной борьбы выступает коммерческий подкуп, который может быть использован зарубежными компаниями для проникновения на российский рынок и уничтожения отечественных производителей.

В условиях обострения конкуренции как между частными фирмами, так и государствами, ужесточения санкций в отношении Российской Федерации со стороны ряда зарубежных стран и их объединений, стремящихся не допустить возрождения России, можно с большой уверенностью ожидать возрастания угроз проведения иностранными специальными разведывательными службами подрывных специальных операций, поощрение ими экстремистских организаций и радикальных общественных объединений, подкупа должностных лиц государственного и муниципального аппарата управления и ведущих российских компаний. 
В-третьих, актуальным является разграничение коррупции на такие её формы, как мздоимство и лихоимство. К мздоимству относится получение неправомерного вознаграждения за совершение законных действий, а к лихоимству - получение неправомерного вознаграждения за совершение незаконных действий. На наш взгляд, лихоимство несет в себе большую общественную опасность, чем мздоимство. Однако в настоящее время разграничение коррупции на эти две формы не находит своего должного отражения в антикоррупционной политике и не учитывается повышенная опасность лихоимства, при котором должностные лица, получая неправомочное вознаграждение, осуществляют незаконные действия.

В-четвертых, коррупцию можно классифицировать согласно статьям Уголовного кодекса Российской Федерации, выделяя при этом, например, дачу взятки, получение взятки, злоупотребление должностными полномочиями и коммерческий подкуп. Принято считать, что коррупционные действия идут в разрез установленным государством нормам права. Однако, выделяя таким образом правовые формы коррупции, нельзя исключать существование других ее форм, которые носят объективный характер и существуют независимо от законотворчества.

Поэтому можно выделить высшую, наиболее опасную форму коррупции, при которой законы установлены в интересах коррумпированных должностных лиц государственных, муниципальных органов власти и частного сектора экономики. В таком случае будет сформирована узаконенная коррупция (коррупция в законе), в результате которой возникает криминальноолигархический капитализм, а должностные лица государственного аппарата начнут обслуживать интересы коррумпированных чиновников и криминальных олигархов. Самым негативным последствием существования узаконенной коррупции станет формирование криминального государства, в котором законодательные, исполнительные, судебные органы власти и даже средства массовой информации функционируют в интересах коррумпированных должностных лиц, а криминальные олигархи начнут создавать собственные вооруженные отряды. Таким образом, можно выделять противозаконную и узаконенную коррупцию, причем степень общественной опасности последней гораздо выше первой.
Экономические корни коррупции, прежде всего ее деловой формы, кроются в теневой экономике. Субъектами коррупционных преступлений могут быть все участники теневой экономики, к которым относятся теневые предприниматели, наемные работники и покупатели (потребители теневых экономических благ). К данным субъектам при определенных обстоятельствах могут присоединиться участники легального рынка в следствии своего оппортунистического поведения, то есть поведения, нацеленного на обман контрагентов с целью увеличения собственной выгоды. Тем самым легальные участники рынка вовлекаются в сферу оборота теневого капитала [5].

Фигурантами уголовных дел о коррупции чаще всего становятся сотрудники правоохранительных органов, должностные лица муниципальных учреждений и предприятий, органов местного самоуправления, образования, здравоохранения, а также военнослужащие [6]. Характеризуя среднестатистический портрет коррупционера, следует отметить, что это мужчина в возрасте 30-49 лет, психологически склонный к коррупционному поведению [7]. Такая среднестатистическая характеристика свидетельствует о том, что необходимо шире использовать психологические приемы отбора кандидатов на руководящие должности, а также применять компьютерные программы, включая проверку на полиграфе.

Последствия коррупции негативны и требуют постоянного государственного вмешательства для их устранения [8]. На наш взгляд, к национальной угрозе нужно относить формирование порочного круга коррупции, разрушающего государственное и муниципальное управление и, как следствие российскую государственность.

В коррупционном рынке участвуют субъекты, как формирующие спрос на коррупционные услуги, так и его удовлетворяющие. Спрос на коррупционные услуги формируют легальные домохозяйства, фирмы и субъекты внешнего рынка, которые стремятся за счет своего коррупционного поведения приобрести конкурентные преимущества. Субъекты теневой экономики задают устойчивый спрос на коррупционные услуги ввиду необходимости обеспечения гарантий продолжения и расширения своей противоправной деятельности. Предложение коррупционных услуг обеспечивается должностными лицами, как государственного, муниципального, так 
и частного сектора экономики.

В результате взаимодействия спроса и предложения определяется цена коррупционной услуги - величина взятки в денежном или ином вещественном эквиваленте, либо иной выгоде. Как со стороны спроса, так и со стороны предложения формируются конкурентные силы, стремящиеся к монополизации рынка коррупционных услуг. Любая монополизация, в том числе и в данном случае, приводит к росту цен. В данном случае происходит увеличение среднего размера взятки.

Получение конкурентных преимуществ за счет коррупционного поведения называется коррупционным оппортунизмом, а увеличение числа участников коррупционных сделок вследствие экономической привлекательности коррупционного поведения - «эффектом коррупции». В результате образуется порочный круг коррупции, который как воронка в реке, затягивает в коррупционный рынок новых участников.

Первым составным элементом порочного круга коррупции выступают теневые доходы как финансовый источник возможного коррупционного поведения людей. Коррупция существует во многом благодаря ее финансовому источнику, к которому относятся полученные или будущие доходы от теневой, прежде всего криминальной деятельности.

Вторым составным элементом порочного круга коррупции служит эффект коррупционного поведения людей, который выступает как частный случай эффекта нарушителя. Участники коррупционных сделок получают конкурентные преимущества по сравнению с другими участниками рынка. Поэтому нарушители закона улучшают свое финансовое благополучие по сравнению с законопослушными субъектами, что притягивает в коррупционные сделки все новых и новых участников.

К третьему составному элементу порочного круга коррупции относятся психологические ожидания коррупционного поведения людей. В условиях коррупционного рынка у его участников со стороны спроса формируются психологические ожидания того, что без коррупционного поведения невозможно совершать какие-либо сделки и другие действия. В тоже время участники со стороны предложения коррупционных услуг ожидают подношения как форму их оплаты. Сформировавшиеся коррупционные ожидания распространяются среди легальных участников рынка, что приводит к увеличению как спроса на коррупционные услуги, так и их предложения. Тем самым расширяются масштабы теневой экономики, увеличиваются теневые доходы и, как следствие, ухудшается инвестиционный климат в Российской Федерации.

Вывоз капитала из России так называемой «элитой» дал основание американскому политологу Бжезинскому заявить: «Вы еще разберитесь, чья это элита - ваша или уже наша. Эта элита никак не связывает свою судьбу с судьбой России. У них деньги уже там, дети уже там...» [9]. В результате усиливается лоббирование иностранных интересов в Российской Федерации.

Поэтому лицам, занимающим государственные должности, должности первого заместителя и заместителей генерального прокурора России, членов совета директоров Банка России, должности в государственных корпорациях, а также должности федеральной государственной службы, назначения на которые осуществляются президентом России, правительством России и генеральным прокурором запрещено открывать и иметь счета (вклады), хранить наличные денежные средства в иностранных банках, расположенных за пределами территории России, и иметь ценные бумаги иностранных эмитентов [10]. Такие же требования предусмотрены на супругов и несовершеннолетних детей указанной категорий чиновников.

В соответствии с законодательством Российской Федерации в целях противодействия возникновению конфликтов интересов и роста коррупции на государственной и муниципальной службе предусмотрено:

1. Подтверждение законности происхождения приобретенного имущества или полученных доходов.

2. Получение согласия на трудоустройство в той или иной компании после увольнения должностного лица.

3. Проведение антикоррупционных экспертиз подзаконных актов.

4. Привлечение к административной ответственности за незаконное вознаграждение от имени юридического лица, при этом сотрудничавшей с коррупционером фирме назначаются штрафы.

5. Увольнение должностного лица в связи с утратой доверия при подозрении в коррупционном поведении.

6. Преследование скрывающихся за рубе- 
жом отечественных чиновников-коррупционеров.

Но в законе не учитывается, что дети чиновников растут и достигают совершеннолетия; супруги могут фиктивно развестись или жить в гражданском браке; у чиновников имеются родители; чиновники могут иметь недвижимое имущество на территории иностранных государств, чьи интересы они вряд ли будут не учитывать, исполняя свои служебные обязанности.

В настоящее время за недостоверные сведения о доходах государственные служащие будут уволены в связи с утратой доверия, однако в случаях с депутатами Государственной Думы и Совета Федерации такую информацию лишь опубликуют в средствах массовой информации и на официальном сайте Счетной палаты.

В случаях не уведомления государственным служащим о конфликте интересов ему объявляется выговор или предупреждение о неполном служебном соответствии. В настоящее время таких мер наказания для членов Совета Федерации и Государственной Думы нет. Поэтому необходимы единые требования как для членов депутатского корпуса, так и для государственных и муниципальных служащих.

Депутаты всех уровней законодательной власти должны наравне с государственными и муниципальными служащими заполнять декларации о своих доходах и расходах. В таких декларациях следует отражать сделки, общая годовая стоимость которых превышает совокупный доход семьи за три предшествовавших отчетному периоду года, а также источники этих расходов.

Ответственность депутатов, государственных и муниципальных служащих должна быть гибкой в зависимости от тяжести совершенных коррупционных правонарушений. Например, если коррупционное правонарушение совершено по неосторожности или в условиях крайней необходимости, то виновному предлагается объявлять предупреждение.

Если депутаты всех уровней, государственные и муниципальные служащие не смогут подтвердить правомочность приобретения имущества на законные доходы своей семьи, то материалы проведенных проверок должны передаваться в суд органами прокуратуры для взыскания этого имущества в доход государства или муниципалитета.

Развитие цифровой экономики приводит к появлению множества различных криптова- лют, которые могут использоваться в коррупционных схемах. Например, в соответствии с принятыми рекомендации по предоставлению сведений о доходах и имуществе чиновников и членов их семей в справке о доходах не нужно указывать виртуальные валюты. Использование криптовалют и анонимность открываемых крипто-кошельков затрудняют раскрытие и расследование преступлений [11].

Для совершения операций по покупке или продаже криптовалют, их использованию в сделках купли-продажи различных товаров и услуг необходимы электронные кошельки с очень высокой степенью защищенности. Однако для коррупционеров главным критерием при выборе крипто-кошелька является его анонимность. Наличие анонимных крипто-кошельков не позволяет осуществлять идентификацию их владельцев и разрушает систему контроля за доходами и имуществом должностных лиц государственного и муниципального аппарата управления. Поэтому для противодействия коррупционному поведению должностных лиц необходимо использовать методы выявления признаков и способов незаконной легализации криминальных доходов.

В настоящее время наиболее распространенной криптовалютой по-прежнему является биткоин, но большинство пользователей даркнета предпочитают более анонимные криптовалюты, например, Monero. Использование анонимных криптовалют не позволяет узнать, кто является субъектом преступлений коррупционной направленности.

Ужесточение контроля за доходами должностных лиц государственных и муниципальных органов власти приведет к тому, что субъекты коррупционных доходов будут использовать способы их легализации. Поэтому одно из направлений борьбы с коррупцией лежит в сфере противодействия легализации (отмыванию) доходов, полученных преступным путем [12].

Под государственным контролем понимается проверка уполномоченными органами государственной власти деятельности как физических, так и юридических лиц, направленная на предупреждение, выявление и пресечение нарушений требований, которые установлены нормативными правовыми актами. По результатам государственного контроля при выявлении нарушений применяются меры государственного принуждения. 
Государственный контроль увеличивает издержки предпринимательской деятельности, и указанный выше механизм эффекта коррупции толкает часть предпринимателей и менеджеров на путь коррупционного поведения. Порочный круг коррупции втягивает в коррупционные схемы психологически неустойчивую часть государственных и муниципальных служащих, поэтому права юридических лиц и индивидуальных предпринимателей в настоящее время законодательно защищены при осуществлении государственного контроля (надзора) и муниципального контроля.

Однако сокращение государственного контроля модифицирует порочный круг коррупции, превращая его в заколдованный круг коррупции, так как ужесточение контроля порождает коррупцию, а уменьшение контроля увеличивает теневые доходы и, как следствие, растет коррупция.

Поэтому, при разработке мер государственной экономической политики противодействия коррупции, необходимо вырабатывать комплексные меры по противодействию коррупционному поведению должностных лиц. Без разрыва порочного круга коррупции борьба с последней обречена на неудачу, так как вовлечение должностных лиц государственных и муниципальных органов власти в кругооборот теневого капитала обеспечивает расширенное воспроизводство теневых экономических отношений.

\section{Библиографический список}

1. ООН подсчитала ежегодный объем взяток в мире.- URL: https://www.gazeta.ru/social/ news/2017/12/10/n_10915682.shtml (дата обращения: 10.12.2017).

2. Генеральной прокуратурой Российской Федерации проанализировано состояние коррупционной преступности по итогам 2019 года. - URL: https://genproc.gov.ru/smi/news/genproc/news-1817130/ (дата обращения: 21.06.2019).

3. Генпрокуратураназваласамыекоррупционныерегионыв России//-URL:https://ria.ru/20200618/1573095348. html?share-block=1573095635 (дата обращения: 20.06.2019).

4. Федеральный закон от 25.12.2008 N 273-Ф3 (ред. от 24.04.2020) «О противодействии коррупции».- URL: http://www.consultant.ru/document/cons_doc_LAW_82959/ (дата обращения: 21.06.2020).

5. Чернов С.Б. Теневой капитал и теневая экономика. / Вестник университета (Государственный университет управления).- М.: ГУУ, 2014 г., № 20, с. 159-165.

6. Бастрыкин назвал наиболее подверженные коррупции профессии - URL: https:/www.gazeta.ru/social/ news/2017/12/07/n_10907036.shtml (дата обращения 07.12.2017).

7. Петров И. Прописали лечение. Как в России применяют новый подход к борьбе с коррупцией.- URL: https://lenta.ru/articles/2017/04/06/corruption/ (дата обращения: 06.04.2017).

8. Чернов С.Б. Коррупция: социально-экономическая характеристика и последствия / Экономические науки, 2014 г., № 11, с. 11-15.

9. Бжезинский о российской элите. Новый Регион, 17 ноября 2011 г.- URL: http://ruscesar.livejournal. com/365074.html (дата обращения: 10.03.2019).

10. Госдума окончательно запретила чиновникам иметь зарубежные счета. - URL: https://www.rbc.ru/politics/2 4/04/2013/570407719a7947fcbd4483c3 (дата обращения: 10.03.2019).

11. Чернов С.Б. Политика противодействия финансированию терроризма: определение и угрозы в условиях развития рынка искусственного интеллекта / Экономические науки. 2019 г., № 7, с. 85-91.

12. Чернов С.Б. Отмывание криминального капитала как угроза безопасности экономики России / Вестник университета (Государственный университет управления). - М.: ГУУ, 2016 г., № 2, с. 98-105. 